\title{
Core-Shell Encapsulation of Salt Hydrates into Mesoporous Silica Shells for Thermochemical Energy Storage
}

\author{
Alexandr Shkatulov,* Rick Joosten, Hartmut Fischer, and Henk Huinink \\ Cite This: ACS Appl. Energy Mater. 2020, 3, 6860-6869 \\ Read Online
}

ABSTRACT: The advent of thermochemical energy storage (TcES), that is, storage of thermal energy by means of reversible chemical reactions, incites finding pathways of stabilization of thermochemical materials for thermal batteries of the future. Currently, salt hydrates such as $\mathrm{LiCl} \cdot \mathrm{H}_{2} \mathrm{O}, \mathrm{CaCl}_{2} \cdot 6 \mathrm{H}_{2} \mathrm{O}$, and $\mathrm{SrBr}_{2} \cdot 6 \mathrm{H}_{2} \mathrm{O}$ are being actively studied for TcES in buildings due to both high energy storage density $\left(1-2.5 \mathrm{GJ} / \mathrm{m}^{3}\right)$ and high storage duration. In this work, we report the core-shell composites "salt in hollow $\mathrm{SiO}_{2}$ spheres with mesopores" ( salt $=\mathrm{LiCl} \cdot \mathrm{H}_{2} \mathrm{O}, \mathrm{CaCl}_{2} \cdot 6 \mathrm{H}_{2} \mathrm{O}, \mathrm{SrBr}_{2} \cdot 6 \mathrm{H}_{2} \mathrm{O}$ ) for domestic TcES. The salt hydrates were encapsulated into submicrometer-sized hollow $\mathrm{SiO}_{2}$ (HS) capsules as confirmed by transmission electron microscopy (TEM) and $\mathrm{N}_{2}$ sorption analyses. High

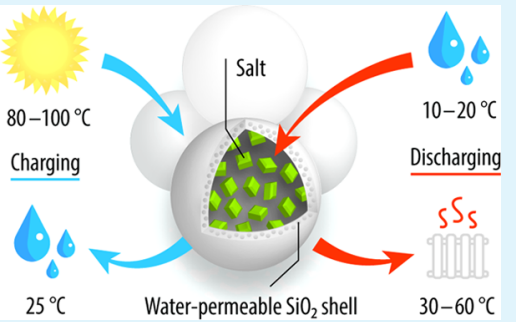
sorption/desorption rates due to mesopores of the shells were shown by thermogravimetric analysis (TGA). The sorption equilibrium for salt@HS was reported, and the applicability of the materials for domestic heat batteries was analyzed. As a result of almost the densest packing of salt@HS, the composites were shown to provide a state-of-the-art energy storage density up to 0.86 $\mathrm{GJ} / \mathrm{m}^{3}$ on the bed level for the high-temperature lift of $32-47^{\circ} \mathrm{C}$, showing high energy storage capacity. The stability in at least 50 charging/discharging cycles was confirmed by TGA and TEM.

KEYWORDS: thermochemical energy storage, adsorptive heat storage, salt hydrates, CSPM, heat storage density, adsorptive cooling

\section{INTRODUCTION}

Salt hydrates $\mathrm{S} \cdot n \mathrm{H}_{2} \mathrm{O}$ represent a class of materials frequently considered suitable for applications such as thermal energy storage $^{1,2}$ and water harvesting from air. ${ }^{3}$ Historically, some of the salt hydrates have been used for drying in their anhydrous form since the early 1800 s (e.g., $\mathrm{CaCl}_{2}$ ), while others, such as $\mathrm{K}_{2} \mathrm{CO}_{3} \cdot 1.5 \mathrm{H}_{2} \mathrm{O}, \mathrm{La}_{2}\left(\mathrm{SO}_{4}\right)_{3} \cdot 2 \mathrm{H}_{2} \mathrm{O}, \mathrm{CaC}_{2} \mathrm{O}_{4} \cdot 2 \mathrm{H}_{2} \mathrm{O}$, or $\mathrm{CaZn}_{2}\left(\mathrm{PO}_{4}\right)_{2} \cdot 2 \mathrm{H}_{2} \mathrm{O}$, have been identified as candidates for applications only recently. ${ }^{4-7}$ The current spike of interest on salt hydrates in general ${ }^{8}$ and on their dehydration/rehydration in particular $^{9}$ is caused by the rapid development of thermochemical energy storage (TcES), that is, storage of heat by means of reversible chemical reactions. This technology provides the most long-term and volume-efficient storage of heat from industrial and renewable sources (e.g., the $\operatorname{Sun}^{10}$ ) for bridging the gap between the heat supply and heat demand, thus saving energy resources. ${ }^{11}$

Among numerous water sorbents that can retain water molecules by van der Waals forces and hydrogen bonds (e.g., zeolites $^{12}$ or MOFs $\left.{ }^{13,14}\right)$, salt hydrates are characterized by high water uptake (in g- $\mathrm{H}_{2} \mathrm{O} / \mathrm{g}$-material) and consequently high heat storage density, as the water molecules are captured in specific positions in a crystal lattice rather than in more disordered adsorbed or condensed states ${ }^{15}$

$$
S \cdot(n-m) \mathrm{H}_{2} \mathrm{O}_{(\text {cr })}+m \mathrm{H}_{2} \mathrm{O}_{(\mathrm{g})}=S \cdot n \mathrm{H}_{2} \mathrm{O}_{(\text {cr })}
$$

Such an ordered state of water in a hydrate lattice makes equilibrium 1 monovariant according to the Gibbs' phase rule, i.e., the hydration or dehydration proceed completely at a specified temperature and partial pressure of water vapor from the thermodynamic point of view. This leads to the simple form of the van ' $t$ Hoff equation describing the equilibrium line between $\mathrm{S} \cdot \mathrm{nH}_{2} \mathrm{O}$ and $\mathrm{S} \cdot(n-m) \mathrm{H}_{2} \mathrm{O}$ in Figure 1

$$
\ln \frac{P_{\mathrm{eq}}}{P^{0}}=-\frac{\Delta_{\mathrm{r}} H^{0}}{R T_{\mathrm{eq}}}+\frac{\Delta_{\mathrm{r}} S^{0}}{R}
$$

where $T_{\text {eq }}[\mathrm{K}]$ and $P_{\text {eq }}[$ bar $]$ are equilibrium temperature and water vapor pressure, respectively, $P^{0}$ is the standard pressure of 1 bar, $\Delta_{\mathrm{r}} H^{0}[\mathrm{~J} / \mathrm{mol}]$ and $\Delta_{\mathrm{r}} S^{0}[\mathrm{~J} /(\mathrm{mol} \cdot \mathrm{K})]$ are molar changes of enthalpy and entropy in the course of hydration, respectively, and $R$ is the gas constant, approximately equal to $8.314 \mathrm{~J} /(\mathrm{mol} \cdot \mathrm{K})$.

The sorption of water molecules by an anhydrous salt (or lower hydrate) is accompanied by the release of heat (process $1)$, while the reverse process of dehydration is endothermic. Dehydration and hydration, therefore, correspond to the charging and discharging of a "thermal battery" during a TcES cycle (Figure 1). Dehydration (charging) may be carried out

Received: April 29, 2020

Accepted: June 29, 2020

Published: June 29, 2020 


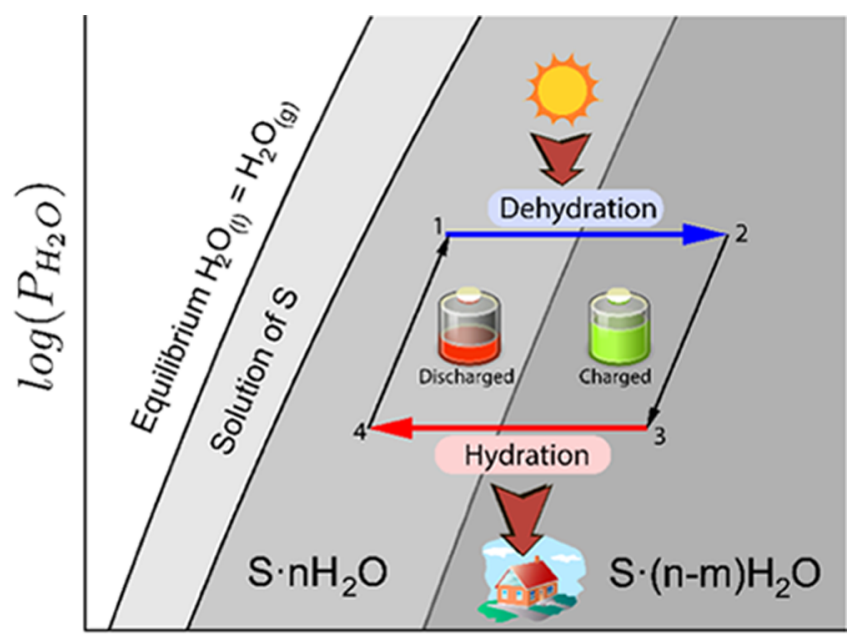

Temperature

Figure 1. TcES cycle on a generic phase diagram for salt hydrates. For heat storage, a salt hydrate $\mathrm{S} \cdot n \mathrm{H}_{2} \mathrm{O}$ in point 1 is isobarically heated by an external heat source, which yields the lower hydrate $S \cdot(n-m) \mathrm{H}_{2} \mathrm{O}$ and water vapor $(1-2)$. After the isosteric transition to point 3 , the hydration of $S \cdot(n-m) \mathrm{H}_{2} \mathrm{O}$ is carried out at lower vapor pressure using, for example, underground water at $0-10{ }^{\circ} \mathrm{C} .{ }^{4}$ During the $3-4$ transition, the released heat is supplied to a consumer. Finally, the isosteric transition $4-1$ is carried out to complete the cycle.

by a renewable heat source at higher water vapor pressure, while the hydration (discharging) releases the useful heat. A thermal battery operating by a $1-2-3-4$ cycle (Figure 1 ) can be used for heating in buildings during wintertime. ${ }^{4}$ Another attractive application is adsorptive cooling when the heat source for dehydration is inside a building while the heat sink (condenser) is outside. In this case, the cycle in Figure 1 is inverted (4-3-2-1).

One of the most important properties for a TcES material is heat storage density. In the literature, there are two main expressions for this parameter referring to the amount of heat that can be stored in a unit mass (gravimetric storage density, GSD) or a unit of volume (volumetric storage density, VSD). Both storage densities are crucial for domestic applications of salt hydrates. The most critical one is VSD, as it determines the volume of the final TcES unit. Typical values of VSD for bulk salt hydrates are $1-3 \mathrm{GJ} / \mathrm{m}^{3}$, which allows long-term domestic heat storage by several cubic meters of the salt for a modern household in Europe. ${ }^{16}$
When the water molecules leave their positions in the course of dehydration according to eq 1 , the former crystal structure of hydrate must be rearranged to the structure of a lower hydrate or even anhydrate. In most cases, such rearrangement, entailing crystal shrinking, is accompanied by mechanical stress that leads to mechanical disintegration of crystals, ${ }^{5,17}$ which is one of the main challenges on the way to direct application of crystallohydrates for TcES. On the other hand, hydration leads to "sintering" of the crystallites due to high surface mobility ${ }^{9}$ or even their complete dissolution in crystalline water if the solution line in Figure 1 is crossed. These two effects dramatically alter the salt morphology in the course of repetitive hydration-dehydration cycles, deteriorating both hydration and dehydration rates. ${ }^{18}$ Therefore, stabilization of salt hydrates for applications is one of the major directions of research in this field in recent years.

The most popular approach so far is the accommodation of a salt hydrate in pores of a matrix that serves both as a rigid shell and a binder. ${ }^{19-21}$ While a plethora of commercial matrices for salt stabilization is reported in the literature, there are just a few popular salts to be stabilized, namely, $\mathrm{CaCl}_{2}{ }^{22}$ $\mathrm{MgSO}_{4}{ }^{18} \mathrm{LiCl}^{23}$ and, since very recently, $\mathrm{SrBr}_{2} \cdot 6 \mathrm{H}_{2} \mathrm{O}{ }^{24,25}$ Typical values of VSD for the composites vary from $0.4 \mathrm{GJ} / \mathrm{m}^{3}$ for composites with a very high bed porosity of $80 \%$ to $1 \mathrm{GJ} /$ $\mathrm{m}^{3}$ for tablets of a composite. It is noteworthy that the authors rarely report the cycling stability of such composites.

While the use of commercially available porous matrices is a mainstream approach for stabilization of TcES materials, the encapsulation technique was overlooked by most researchers. This popular technique ${ }^{26,27}$ was successfully applied to stabilization of phase change materials, ${ }^{28-31}$ which, however, have 3-5 times lower GSD and VSD values in comparison with TcES materials. ${ }^{32}$ The encapsulation of salt hydrates for TcES is complicated by the necessity of mass transport through the capsule shells, which must be facilitated by pores. To the best of our knowledge, the only example of such encapsulation of a thermochemical material into porous shells is reported in ref 33 .

In this work, we report a novel technique for encapsulation of salt hydrates into a permeable porous $\mathrm{SiO}_{2}$ shell for thermochemical energy storage with high storage density on the bed level. The $\mathrm{SiO}_{2}$ capsules with porous shells are prepared first by facile and inexpensive synthesis based on soft templating by a reusable poly( $\mathrm{N}$-isopropylacrylamide) (PNI$\mathrm{PAm}$ ) polymer. Three salts, namely, $\mathrm{LiCl}, \mathrm{CaCl}_{2}$, and $\mathrm{SrBr}_{2}$, are chosen for the encapsulation with emphasis on the properties of $\mathrm{LiCl} @ \mathrm{HS}$ as one of the most promising

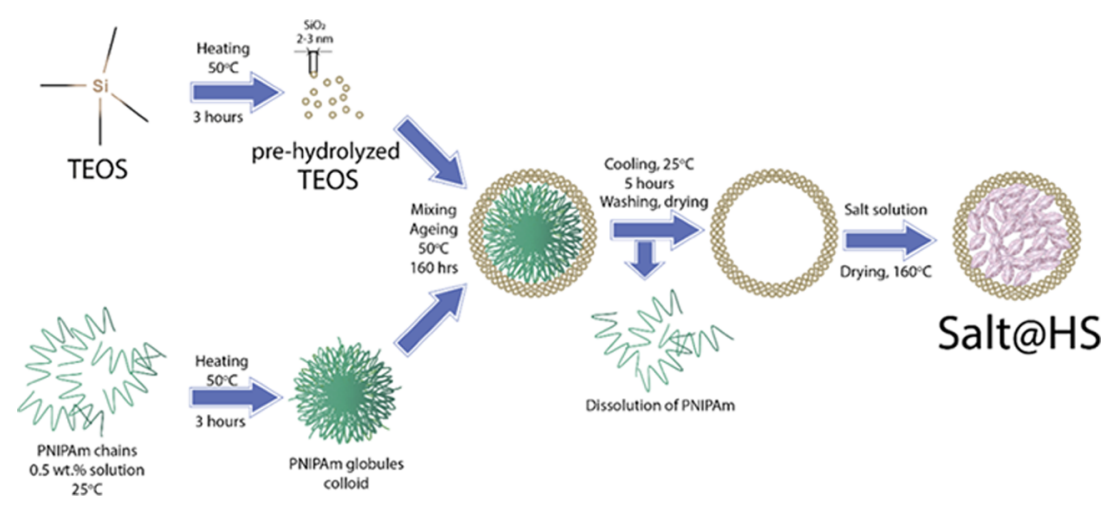

Figure 2. Scheme of preparation of the Salt@HS composites. 
candidates for domestic applications. The emphasis is made on the cycling stability of materials and their energy storage density.

\section{EXPERIMENTAL SECTION}

2.1. Composites Preparation. The porous silica shells, hereinafter referred to as HS (Hollow Silica), were synthesized by a slightly modified soft templating method from ref 34 . This method consists of hydrolysis of tetraethoxysilane (TEOS, Sigma Aldrich, $>99.0 \%$, CAS 78-10-4) at $\mathrm{pH} \sim 7$ in the presence of the particles of the soft template poly $\left(N\right.$-isopropylacrylamide) (PNIPAm, Sigma Aldrich, $M_{\mathrm{W}}$ $\sim 30$ 000-40 000, mp $96{ }^{\circ} \mathrm{C}$, CAS 25189-55-3).

The PNIPAm template particles were prepared by heating $100 \mathrm{~mL}$ of the PNIPAm solution ( $0.5 \mathrm{wt} \%)$ in demineralized water (>15 $\mathrm{M} \Omega / \mathrm{cm}$, ELGA DV25) from room temperature to $50{ }^{\circ} \mathrm{C}$ and stirring for $3 \mathrm{~h}$. As the final temperature was above $31^{\circ} \mathrm{C}$, which is the lower critical solution temperature for the polymer (above this temperature the polymer and water are immiscible), the translucent solution became turbid, indicating the formation of PNIPAm spherical template particles (Figure 2). The stabilization of the colloid was achieved by adding $100 \mu \mathrm{L}$ of $0.05 \mathrm{M} \mathrm{NaOH}$ solution to the initial translucent solution to decrease $\zeta$-potential of the PNIPAm particles. $^{35}$

The prehydrolyzed silica was prepared by adding $4.5 \mathrm{~mL}$ of TEOS to $36 \mathrm{~mL}$ of the demineralized water, followed by stirring at $50{ }^{\circ} \mathrm{C}$ for $3 \mathrm{~h}$. Then, the hot PNIPAm template solution was added to the prehydrolyzed TEOS solution at $50{ }^{\circ} \mathrm{C}$. The mixture was left stirring at $50{ }^{\circ} \mathrm{C}$ for $160 \mathrm{~h}$ to complete the hydrolysis and ripening of the product. Such a long time is required to completely hydrolyze the TEOS and let the capsules ripen at neutral $\mathrm{pH}$. The hydrolysis could $\mathrm{be}$, in principle, accelerated by altering the $\mathrm{pH}$ of the solution to facilitate the manufacturing procedure. In this case, however, the textural properties may be different. After the ripening, the slurry was cooled down to room temperature, which leads to the dissolution of the PNIPAm template. The white suspension of the product was centrifuged (Heraeus Primo R, $4000 \mathrm{rpm}, 20{ }^{\circ} \mathrm{C}, 2 \mathrm{~h}$ ) and washed with water. The centrifugation-washing was repeated four times to purify the product from the residues of PNIPAm. Finally, vacuum drying at room temperature was carried out to obtain the final product (HS).

The water capacity of $\mathbf{H S}$ capsules was evaluated by adding droplets of water to a specimen of the dry material ( $\sim 1 \mathrm{~g}$ of HS, $5 \mu \mathrm{L}$ step). The water capacity was deemed to be reached when the powder became sticky to a glass wall of a vial. The value of water capacity of $1.4 \mathrm{~mL} / \mathrm{g}$ HS was used for the preparation of the salt@HS composites.

The salt@HS composites were prepared by dry impregnation of HS with solutions of $\mathrm{LiCl}, \mathrm{CaCl}_{2}$, and $\mathrm{SrBr}_{2}, 1.4 \mathrm{~mL}$ of solution per 1 $\mathrm{g}$ of $\mathbf{H S}$ (Figure 2 and Table 1). After adding the salt solution, the

Table 1. Solution Concentrations (in $\mathrm{g}$ of a Dry Salt per 1 mL of Solution) and the Salt Content $w$ in the Dry salt@HS Composites

\begin{tabular}{lccc} 
composite & $\begin{array}{c}\text { salt concentration } \\
(\mathrm{g} / \mathrm{mL})\end{array}$ & $\begin{array}{c}w \\
(\text { wt } \%)\end{array}$ & $\begin{array}{c}\text { apparent bed density } \\
\left(\mathrm{g} / \mathrm{cm}^{3}\right)\end{array}$ \\
$\mathbf{L i C l} @ \mathrm{HS}$ & 0.580 & 45 & $0.830 \pm 0.08$ \\
$\mathrm{CaCl}_{2} @ \mathrm{HS}$ & 0.704 & 50 & $0.78 \pm 0.08$ \\
$\mathrm{SrBr}_{2} @ \mathrm{HS}$ & 1.040 & 59 & $0.930 \pm 0.08$ \\
\hline
\end{tabular}

materials were left for $1 \mathrm{~h}$ to complete impregnation. The vacuum drying at room temperature was performed afterward to crystallize the salt hydrates from the solutions. The hydrate water was then removed by complete drying at $160^{\circ} \mathrm{C}$ overnight, except for $\mathrm{SrBr}_{2}$ in which the salt was left in the form of monohydrate $\mathrm{SrBr}_{2} \cdot \mathrm{H}_{2} \mathrm{O}$ by drying at 80 ${ }^{\circ} \mathrm{C}$. The prepared materials will be referred to as LiCl@HS, $\mathrm{CaCl}_{2} @$ HS, and $\mathrm{SrBr}_{2} @ H S$, depending on the salt. The values of the salt weight content $w$ determined by weighing were close to the calculated ones (Table 1). Apparent densities in Table 1 are related to the asprepared powder of the composites.

2.2. Characterization. 2.2.1. Transmission Electron Microscopy (TEM). TEM images were obtained on a Tecnai T20 $\mathrm{G}^{2}$ (Thermo Fisher Scientific), equipped with a $\mathrm{LaB}_{6}$ electron source and a CETA $16 \mathrm{M} 4 \mathrm{k} \times 4 \mathrm{k}$ CMOS camera. The microscope was operated at 200 $\mathrm{kV}$ acceleration voltage in bright-field TEM mode at a nominal magnification of $25000 \times$ with a pixel size of $8.53 \AA$; at $50000 \times$ magnification with a pixel size of $4.24 \AA$; at $80000 \times$ magnification with a pixel size of $2.67 \AA$; or at $100000 \times$ magnification with a pixel size of $2.13 \AA$, all with a $1 \mathrm{~s}$ image acquisition time. For the preparation of a TEM specimen, a $1 \mathrm{wt} \%$ suspension of a sample in absolute ethanol (VWR, $<0.5 \%$ of water) was ultrasonicated for 15 min. Then, a $20 \mu \mathrm{L}$ droplet of the suspension was drop cast onto a CF200-Cu copper grid covered by a continuous carbon film that was prior to deposition surface plasma treated for $40 \mathrm{~s}$ at $5 \mathrm{~A}$ using a Cressington 208 carbon coater. After drying of the dispersant, the TEM grid was immediately placed in the TEM holder, inserted into the microscope, and pumped to high vacuum.

2.2.2. Scanning Electron Microscopy (SEM). SEM images were collected on FEI Quanta 600 with the accelerating voltage of the electron beam of $10 \mathrm{kV}$ and a secondary electron detector. A dry powder of a sample was placed on an aluminum stage covered with gluing carbon tape. Then, the sample was immediately fixed in the microscope chamber to minimize the exposition in air. The chamber was then vacuumed down to $3 \times 10^{-5}$ mbar.

2.2.3. Low-Temperature $\mathrm{N}_{2}$ Adsorption. Low-temperature $\mathrm{N}_{2}$ Adsorption isotherms were measured volumetrically at $77.3 \mathrm{~K}$ using a NOVA 1200 e pore analyzer (Quantachrome Instruments). Both adsorption and desorption isotherms were collected at $P / P^{0}=0.003-$ 0.992 . Before a measurement, a sample $(\sim 100 \mathrm{mg})$ was degassed in vacuum at $150{ }^{\circ} \mathrm{C}$ for $48 \mathrm{~h}$. The surface area was calculated by the BET method with the area of the $\mathrm{N}_{2}$ molecule taken as $0.162 \mathrm{~nm}^{2}$ and $P / P^{0}=0.05-0.35$. The error of the surface area measurement was estimated to be $0.1 \mathrm{~m}^{2} / \mathrm{g}$ for all of the materials. The average pore diameter and pore volume were evaluated by applying the $\mathrm{BJH}$ method to the desorption isotherms. NovaWin software was used for the analysis of the isotherms.

2.2.4. Powder X-ray Diffraction (PXRD) Analysis. PXRD analysis was carried out using a Rigaku Miniflex $600 \mathrm{X}$-Ray diffractometer $(\theta-$ $2 \theta$ geometry) equipped with an $\mathrm{X}$-ray generator $(\mathrm{Cu} \mathrm{K} \alpha$ radiation filtered with Be monochromator, $\lambda=1.5419 \AA, 40 \mathrm{kV}, 15 \mathrm{~mA}$ ), a D/ tex Ultra2 1D detector, and an Anton Paar BTS 500 chamber for temperature and humidity control. The humidity control was carried out by a home-made humidity generator calibrated using deliquescence points of salts ( $\mathrm{LiCl}, \mathrm{MgCl}_{2} \cdot 6 \mathrm{H}_{2} \mathrm{O}, \mathrm{Mg}\left(\mathrm{NO}_{3}\right)_{2}$. $6 \mathrm{H}_{2} \mathrm{O}$ ). Before scanning, the dry samples were powdered using an agate mortar and pestle, placed in a Ni sample holder, and dried in situ at $120^{\circ} \mathrm{C}$ for $2 \mathrm{~h}$ in the flow of dry air $(800 \mathrm{~mL} / \mathrm{min})$. Then, the chamber was cooled down to room temperature and the PXRD patterns were collected in the $2 \theta$ range of $10-75^{\circ}\left(0.02^{\circ}\right.$ scanning step, $1 \mathrm{~s}$ accumulation time). Rigaku PDXL2 software was used to analyze the PXRD data.

2.3. Sorption Properties. 2.3.1. Sorption Equilibrium. Sorption equilibrium was studied using a dynamic vapor sorption (DVS) thermogravimetric method with Q5000 SA thermobalance from TA Instruments (Figure S6a). In a typical experiment, a sample (10-15 $\mathrm{mg}$ ) was placed in a metalized quartz crucible and dried in situ at 80 ${ }^{\circ} \mathrm{C}$ under a flow of $\mathrm{N}_{2}(200 \mathrm{~mL} / \mathrm{min})$; thus, the mass of a dry sample, $m_{\mathrm{d}}$, was determined. Then, the measuring cell was cooled down to the desired temperature $\left(45-60{ }^{\circ} \mathrm{C}\right)$ and water vapor was introduced by mixing dry and wet $\mathrm{N}_{2}$ flows inside the apparatus, thus keeping the constant relative humidity value in the range of $1-75 \%$. After the introduction of water vapor, the weight gain was registered and the equilibrium values $m_{\mathrm{eq}}$ (relative humidity $(\mathrm{RH})$ ) were used to calculate the equilibrium water sorption $w$ in $\mathrm{g}-\mathrm{H}_{2} \mathrm{O}$ per $1 \mathrm{~g}$ of the composite and $a$ in mol- $\mathrm{H}_{2} \mathrm{O}$ per $1 \mathrm{~mol}$ of the salt

$$
w[g / g]=\frac{m_{\mathrm{eq}}-m_{\mathrm{d}}}{m_{\mathrm{d}}}
$$




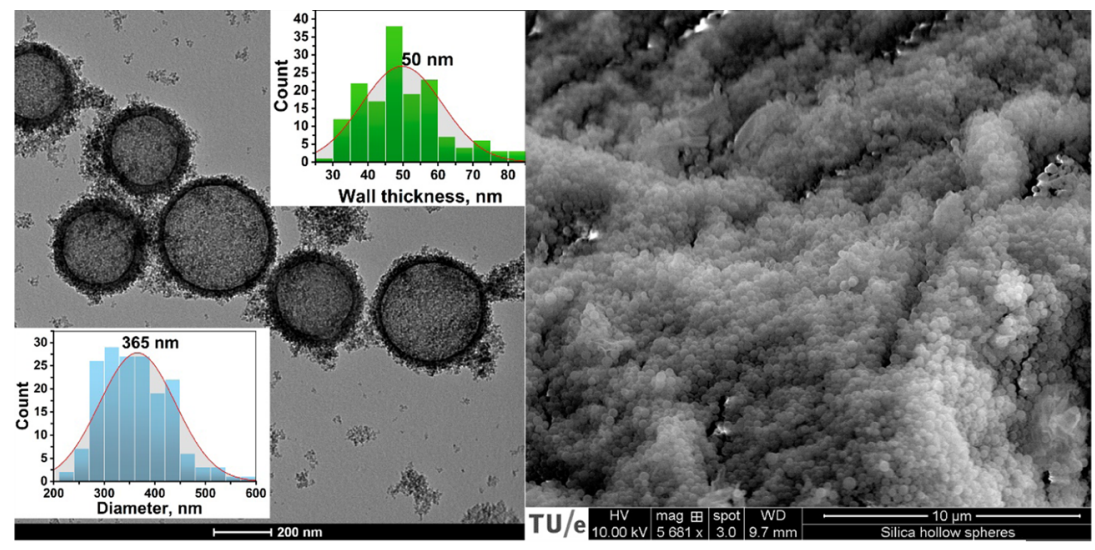

Figure 3. TEM (left) and SEM (right) images of the hollow mesoporous silica spheres (HS). The distributions of the diameter and wall thickness (in $\mathrm{nm}$ ) determined by analysis of multiple TEM images acquired at $25 \mathrm{k} \times$ magnification are shown in the insets. The packing of the as-prepared spheres is illustrated by the SEM image with a lower magnification of $5.7 \mathrm{k} \times$.

$$
a[\mathrm{~mol} / \mathrm{mol}]=\frac{\left(\frac{m_{\mathrm{eq}}-m_{\mathrm{d}}}{M_{\mathrm{H}_{2} \mathrm{O}}}\right)}{\left(\frac{m_{\mathrm{d}} w}{M_{\mathrm{S}}}\right)}
$$

where $M_{\mathrm{H}_{2} \mathrm{O}}$ and $M_{\mathrm{s}}$ are molar masses of water and dry salt, respectively. The error of the weight measurement was estimated to be $\pm 1 \times 10^{-6} \mathrm{~g}$.

2.3.2. Sorption Kinetics. Sorption kinetics for the composite powder was studied by thermogravimetric analysis using the Mettler TGA/DSC 3+ apparatus (Figure S6b) equipped with a home-made humidifier calibrated using deliquescence points of inorganic salts ( $\left.\mathrm{LiCl}, \mathrm{MgCl}_{2}, \mathrm{~K}_{2} \mathrm{CO}_{3}, \mathrm{CH}_{3} \mathrm{COOK}\right)$. A sample $(8-10 \mathrm{mg}$ ) was placed in a $40 \mu \mathrm{L}$ crucible without a lid and put into the measurement chamber. After drying at an elevated temperature $\left(120{ }^{\circ} \mathrm{C}\right.$ for $\mathrm{CaCl}_{2} @ \mathrm{HS}$ and LiCl@HS and $80{ }^{\circ} \mathrm{C}$ for $\mathrm{SrBr}_{2} @ \mathrm{HS}$ ) under a flow of dry $\mathrm{N}_{2}(300 \mathrm{~mL} / \mathrm{min})$ to remove the adsorbed water, the sample was cooled down to the desired temperature. After the introduction of the water vapor into the $\mathrm{N}_{2}$ flow, the weight gain curve was registered. The hydration fraction $\alpha(t)$ was determined as follows

$$
\alpha(t)=\frac{m(t)-m_{\mathrm{d}}}{m_{\mathrm{eq}}-m_{\mathrm{d}}}
$$

2.3.3. Cycling Stability. Cycling stability was studied by TGA (Mettler Toledo TGA/DSC 3+ setup). A sample was placed in a 40 $\mu \mathrm{L}$ crucible without a lid. After the preliminary drying step, the cycling was carried out by temperature swinging while maintaining water vapor pressure in a flow of $\mathrm{N}_{2}(300 \mathrm{~mL} / \mathrm{min})$ constant.

\section{RESULTS AND DISCUSSION}

3.1. Characterization. According to the results of TEM (Figure 3a), the HS particles are hollow spheres with an average diameter of $365 \mathrm{~nm}$ and an average wall thickness of $50 \mathrm{~nm}$. Some debris around the particles is present due to ultrasonication. The BET analysis of $\mathrm{N}_{2}$ sorption isotherms showed that the mesopores $(d<50 \mathrm{~nm})$ with an average diameter of $10 \mathrm{~nm}$ and a total pore volume of $0.24 \mathrm{~cm}^{3} / \mathrm{g}$ are present in the material.

The water capacity calculated from average dimensions and pore volume analysis was $1.37 \pm 0.01 \mathrm{~cm}^{3} / \mathrm{g}$ (Table $S 1$ in the Supporting Information, SI), which is very close to the experimentally determined value $1.4 \mathrm{~cm}^{3} / \mathrm{g}$ (see Section 2). The spheres in the as-prepared HS appear to be densely packed (Figure $3 \mathrm{~b}$ ), which was confirmed by the calculation of the packing factor (PF). The PF value for the $\mathbf{H S}$ was found to be 0.67 (Table $S 1$ in the SI), which is quite close to 0.74 for the densest packing of unidimensional spheres. ${ }^{36}$ Such high PF results in high apparent densities of the composite beds (Table 1), e.g., the apparent densities of $\mathrm{CaCl}_{2} @ \mathrm{HS}$ and $\mathrm{SrBr}_{2} @ \mathrm{HS}$ exceed 0.64 and $0.62 \mathrm{~g} / \mathrm{cm}^{3}$ reported for the corresponding state-of-the-art composites with MIL-101(Cr). ${ }^{22,37}$

The XRD analysis of the salt@HS composites showed the presence of anhydrous salts for the dry materials with traces of $\mathrm{CaCl}_{2} \cdot 2 \mathrm{H}_{2} \mathrm{O}$ for $\mathbf{C a C l}_{2} @ \mathrm{HS}$ (Figure 4). The silica shells exhibited a very broad peak around $2 \theta=21^{\circ}$, indicating that the size of the coherent scattering regions for $\mathrm{SiO}_{2}$ does not exceed several nanometers.

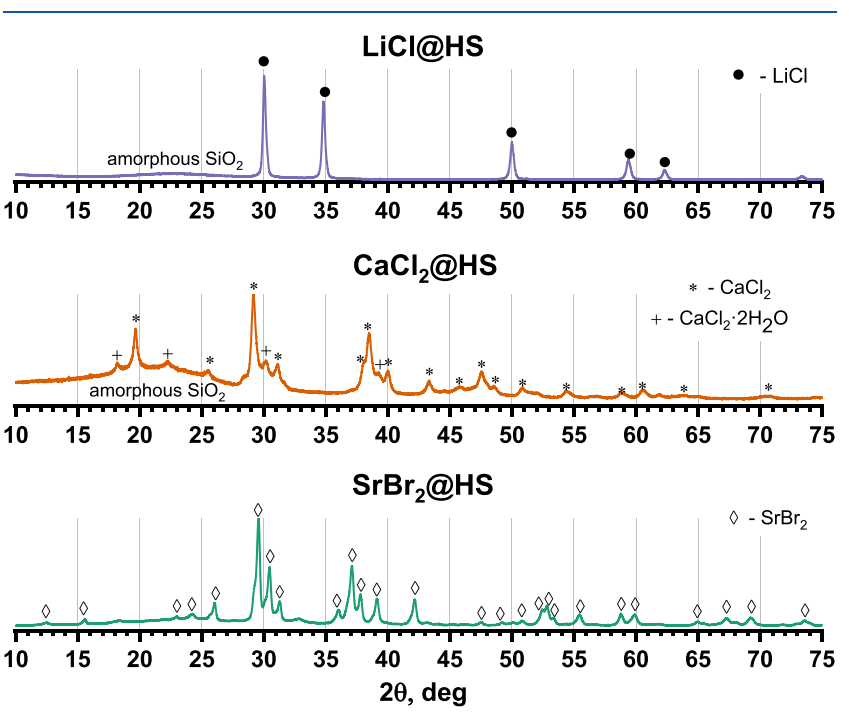

Figure 4. XRD patterns of the dried salt@HS composites.

The encapsulation of the salts into the spheres was confirmed by TEM (Figure 5). The uneven contrast suggests the porosity of the spheres as the salt occurs in the form of multiple crystallites. The contrast between the core and the shell is poor, which may suggest that the salt is also partially localized in the shell, which is confirmed by the decrease of the pore volume (Table 2) and equilibrium behavior (see Section 3.2.1). In total, about 75\% of the shells in LiCl@HS, excluding too large or broken ones, were loaded with the salt (see Figure S4 in the SI for extra TEM images). The visible breaking of the shells may be due to ultrasonication, which was used for the specimen preparation for TEM. This is also confirmed by SEM 


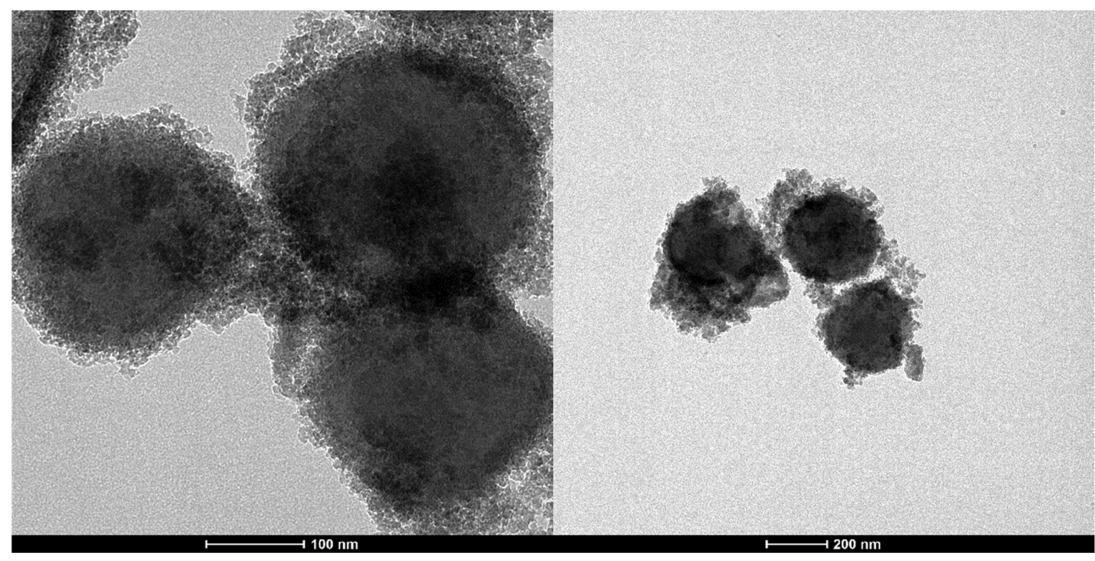

Figure 5. TEM images acquired at $80 \mathrm{k} \times$ of LiCl@HS (left) and $25 \mathrm{k} \times$ of $\mathbf{S r B r}_{2} @ \mathrm{HS}$ (right).

Table 2. Texture Properties of HS and LiCl@HS Based on Analysis of $\mathrm{N}_{2}$ Sorption Isotherms (Figure S1)

$\begin{array}{lccc}\text { composite } & \text { specific surface area }\left(\mathrm{m}^{2} / \mathrm{g}\right) & V_{\mathrm{p}},\left(\mathrm{cm}^{3} / \mathrm{g}\right) & D_{\mathrm{av}}(\mathrm{nm}) \\ \mathbf{H S} & 78.3 & 0.24 & 10.8 \\ \mathrm{LiCl} @ \mathrm{HS} & 43.5 & 0.05 & 7.2 \\ \mathrm{CaCl}_{2} @ \mathrm{HS} & 64.4 & 0.06 & 8.4 \\ \mathrm{SrBr}_{2} @ \mathrm{HS} & 53.6 & 0.08 & 9.2\end{array}$

images where no broken particles or $\mathrm{LiCl}$ crystals outside the capsules were observed (Figure S3 in the SI). Thus, the hollow mesoporous silica capsules were prepared and impregnated with several salts as confirmed by TEM, XRD, and analysis of $\mathrm{N}_{2}$ sorption isotherms.

3.2. Water Sorption Properties. 3.2.1. Sorption Equilibrium. Measurements of water sorption isotherms showed that the $\mathrm{HS}$ takes up to $0.05 \mathrm{~g} / \mathrm{g}$ of water $\left(\mathrm{T}=45^{\circ} \mathrm{C}, \mathrm{P}\left(\mathrm{H}_{2} \mathrm{O}\right)=57\right.$ mbar) due to adsorption. The adsorption isotherm is almost linear in accordance with the pore size distribution (Figure S2 SI).

Introduction of salts into HS dramatically affects the sorption behavior (Figure 6a). First, physical adsorption is followed by a sharp increase of loading due to the formation of the salt hydrates

$$
\mathrm{LiCl}_{(\mathrm{cr})}+\mathrm{H}_{2} \mathrm{O}_{(\mathrm{g})}=\mathrm{LiCl} \cdot \mathrm{H}_{2} \mathrm{O}_{(\mathrm{cr})}
$$

$$
\begin{aligned}
& \mathrm{CaCl}_{2(\mathrm{cr})}+\mathrm{H}_{2} \mathrm{O}_{(\mathrm{g})}=\mathrm{CaCl}_{2} \cdot 2 \mathrm{H}_{2} \mathrm{O}_{(\mathrm{cr})} \\
& \mathrm{CaCl}_{2} \cdot 2 \mathrm{H}_{2} \mathrm{O}_{(\mathrm{cr})}+2 \mathrm{H}_{2} \mathrm{O}_{(\mathrm{g})}=\mathrm{CaCl}_{2} \cdot 4 \mathrm{H}_{2} \mathrm{O}_{(\mathrm{cr})} \\
& \mathrm{SrBr}_{2} \cdot \mathrm{H}_{2} \mathrm{O}_{(\mathrm{cr})}+5 \mathrm{H}_{2} \mathrm{O}_{(\mathrm{g})}=\mathrm{SrBr}_{2} \cdot 6 \mathrm{H}_{2} \mathrm{O}_{(\mathrm{cr})}
\end{aligned}
$$

The values of transition pressure for all of the transformations 6-9 are in good agreement with the ones calculated from the thermodynamic parameters of these processes. ${ }^{4,38}$ Thus, confinement into the capsules does not alter the thermodynamic parameters of the crystalline salts. After the formation of a salt hydrate, a plateau on the sorption isotherms is observed for all of the salt hydrates, except for $\mathrm{CaCl}_{2} \cdot 4 \mathrm{H}_{2} \mathrm{O}$. The plateau is followed by the deliquescence of the salt. The formation of a solution in the capsules leads to continuous absorption of water vapor, which can be observed as a steep increase of the water uptake on the sorption isotherms. The deliquescence for $\mathrm{SrBr}_{2} @ \mathrm{HS}$ and LiCl@HS starts earlier than the deliquescence of the salts in bulk (10 and 58 mbar, respectively ${ }^{39,40}$ ) and appears "smeared" on the isotherms. This confirms that part of the salt is located in the mesoporous shell since the deliquescence $\mathrm{RH}$ is lowered for the salts confined in the mesoporous matrices due to the interaction with the silica surface. $^{41}$

The maximal amount of absorbed water is determined by the concentration of the salt solutions that were used for the (a)

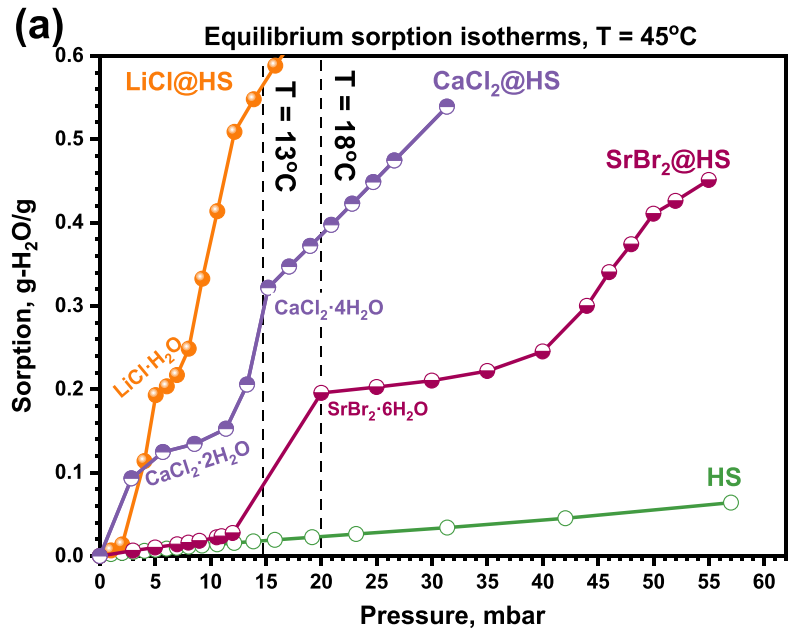

(b)

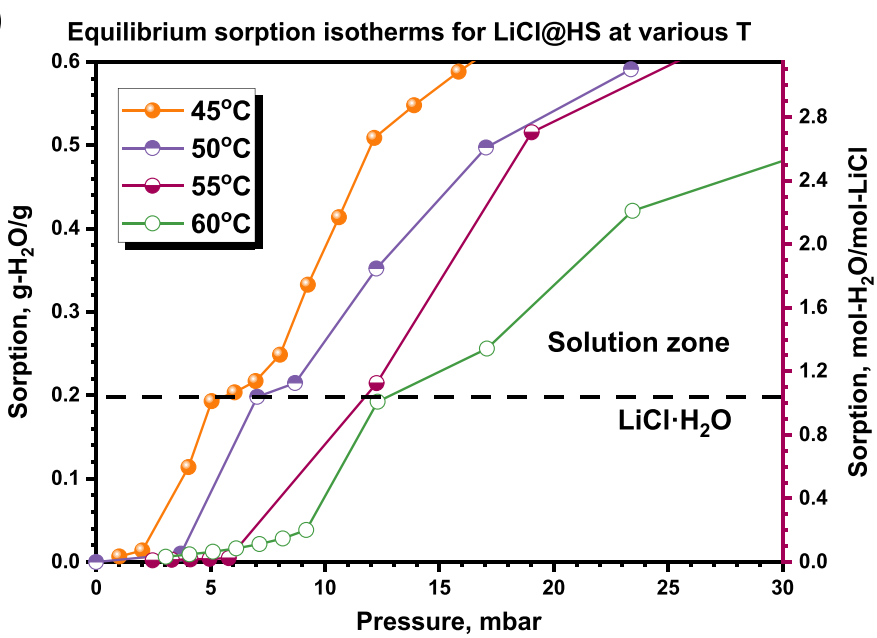

Figure 6. Equilibrium water sorption isotherms for salt@HS (a) and for LiCl@HS at T=45-60 ${ }^{\circ} \mathrm{C}$ (b). 


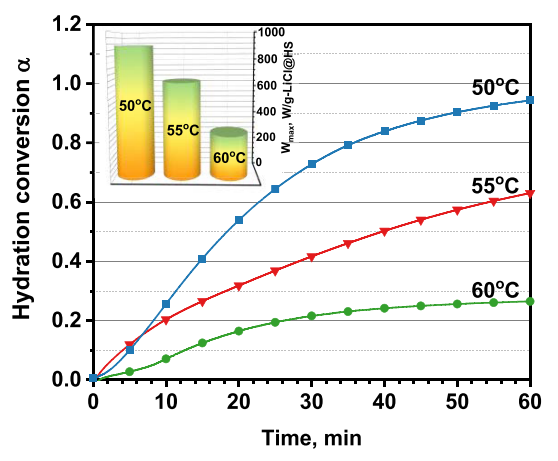

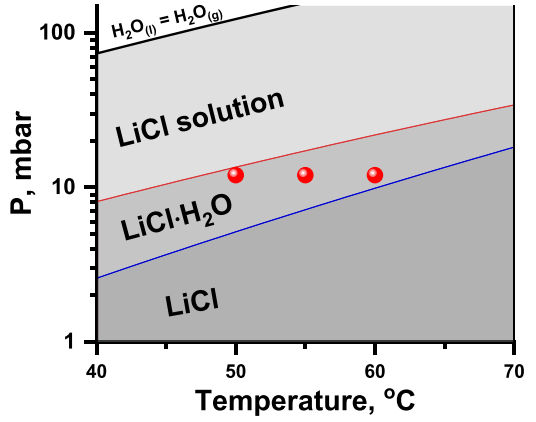

b

Figure 7. Hydration kinetic curves for anhydrous $\mathrm{LiCl} @ \mathrm{HS}$ at a water vapor pressure of $12 \mathrm{mbar}(\mathrm{a})$ and experimental conditions on a $P-T$ phase diagram for the $\mathrm{LiCl}-\mathrm{H}_{2} \mathrm{O}$ system (b). The conversion $\alpha$ was calculated assuming the process $\mathrm{LiCl}+\mathrm{H}_{2} \mathrm{O}=\mathrm{LiCl} \cdot \mathrm{H}_{2} \mathrm{O}$, meaning that $\alpha=1$ corresponds to the full conversion of anhydrous $\mathrm{LiCl}$ to the monohydrate. The maximal values of heat release power are shown by the inset graph.

preparation of the materials. Once this threshold is reached, the volume of the solution exceeds the "useful" volume of the capsules and the solution starts filling the space between the capsules, thus removing the salt from them. The threshold values are represented by the last points of isotherms in Figure 6a.

The sorption behavior of the composites makes possible the realization of the heat storage cycles charged by solar radiation at $\mathrm{T}=80-100{ }^{\circ} \mathrm{C}$ and discharged at $45{ }^{\circ} \mathrm{C}$ using a lowtemperature heat at $T=13{ }^{\circ} \mathrm{C}$ for $\mathbf{L i C l} @ \mathrm{HS}$ or $\mathbf{C a C l}_{2} @ \mathrm{HS}$ and $T=18{ }^{\circ} \mathrm{C}$ for $\mathrm{SrBr}_{2} @ H S$ (e.g., from groundwater). Such heat can be used for space heating. One of the other envisaged applications is the production of hot tap water. According to the modern standards of living, the water should be warmed up at least to $55-60{ }^{\circ} \mathrm{C}$ to be used in buildings. ${ }^{4}$ The composite LiCl@HS allows realization of such a cycle by absorbing water as one can observe from Figure $6 \mathrm{~b}$. The analysis of the heat storage density is carried out in Section 3.3.

Thus, the encapsulation does not affect the solid-solid transitions while smears the deliquescence transition, presumably, due to part of the salt confined in the mesopores of the shells.

3.2.2. Sorption Kinetics. Heat release power on a reactor level is limited by the kinetics of the hydration on the low-scale level. LiCl@HS can be hydrated almost completely at $T=50$ ${ }^{\circ} \mathrm{C}$ and $P\left(\mathrm{H}_{2} \mathrm{O}\right)$ of $12 \mathrm{mbar}$ (evaporation temperature $T_{\mathrm{e}}=10$ ${ }^{\circ} \mathrm{C}$ ) for $1 \mathrm{~h}$ (Figure 7 ), which gives average heat release power of $170 \mathrm{~W} / \mathrm{kg}-\mathrm{LiCl} @ \mathrm{HS}$ or $142 \mathrm{~W} / \mathrm{m}^{3}$-bed. These values are high enough for applications. ${ }^{16}$

Maximal power of heat release $W_{\max }$ was calculated in the assumption that a material gains weight only due to the hydration reaction and not absorption (i.e., no deliquescence) or adsorption on the surface

$$
W_{\max }=\Delta_{\mathrm{r}} H^{0} \max \left(\frac{\mathrm{d} \alpha}{\mathrm{d} t}\right)
$$

where $\Delta_{\mathrm{r}} H^{0}$ is a standard enthalpy change for the hydration. The maximal power of heat release for LiCl@HS increases from 230W/kg-LiCl@HS at $60{ }^{\circ} \mathrm{C}$ to $920 \mathrm{~W} / \mathrm{kg}-\mathrm{LiCl} @ \mathrm{HS}$ at $50{ }^{\circ} \mathrm{C}$. These values indicate that heat can be readily released by LiCl@HS under conditions promising for space heating and hot tap water production.

It should be mentioned that for analyzing the kinetics, only chemical reaction 6 was taken into account. This might not be entirely true for $T=50{ }^{\circ} \mathrm{C}$ since part of the salt confined in the shells might get into the deliquescence (Figure $7 \mathrm{~b}$ ). Therefore, the power value calculated under such assumptions for $T=50$ ${ }^{\circ} \mathrm{C}$ is somewhat overestimated.

It is noteworthy that since the kinetic analysis was performed under the flow of gas, the experimental conditions can represent only an open system, not a closed one. Moreover, in large adsorbent beds, the power may be affected by transport phenomena such as heat or mass transfer. Bearing this in mind, the results therefore should be considered as the first qualitative kinetic tests. While the design of an adsorber is beyond the scope of the present work, from the kinetics data, we conclude that the hydration of the core-shell composite LiCl@HS is fast enough and is unlikely to be hindered by the encapsulation, which renders this material promising for applications from the point of view of reaction rates.

3.3. Energy Storage Density under Conditions of a Domestic Heating Cycle. Energy storage density is a crucial parameter that makes thermochemical energy storage advantageous over traditional sensible and latent heat storage. For the composites, this parameter strongly depends on the conditions of a thermochemical cycle since the sorption mechanisms may differ. If the initial state is $\mathrm{LiCl}, \mathrm{CaCl}_{2}$, or $\mathrm{SrBr}_{2} \cdot \mathrm{H}_{2} \mathrm{O}$ and the final state is a salt solution, the gravimetric storage density (GSD) may be calculated by summing the reaction enthalpy (for the processes (6)-(9)), melting enthalpy of the highest hydrate, and dilution enthalpy (the data are taken from refs 24 , $38,42-44$ )

$$
\begin{aligned}
\mathrm{GSD} & =\frac{\Delta_{\mathrm{r}} H^{0}}{M}+\Delta_{\mathrm{m}} H^{0}+\int_{a_{0}}^{a} \Delta_{\mathrm{ab}} H^{0}(a) \mathrm{d} a \\
\mathrm{VSD} & =\mathrm{GSD} \times \rho
\end{aligned}
$$

where $M$ is the molar mass, $\rho_{\text {bed }}$ is the bed density, $\Delta_{\mathrm{r}} H^{0}$, $\Delta_{\mathrm{m}} H^{0}$, and $\Delta_{\mathrm{ab}} H^{0}$ are reaction, melting, and absorption enthalpies, respectively, and the initial sorption $a_{0}$ corresponds to the highest hydrate, while the total sorption $a$ is determined from the sorption isotherms (Figure 6) for specific cycle conditions.

In this work, we report both GSD and VSD for several thermochemical cycles, namely, $T_{\mathrm{e}}=13$ or $18{ }^{\circ} \mathrm{C}, \mathrm{T}_{\mathrm{h}}=45^{\circ} \mathrm{C}$ (we will refer to them as $13 / 45$ and $18 / 45$ cycles) for space heating and $T_{\mathrm{e}}=13{ }^{\circ} \mathrm{C}, \mathrm{T}_{\mathrm{h}}=60{ }^{\circ} \mathrm{C}(13 / 60$ cycle $)$ for hot tap water production. Under the conditions of the $13 / 45$ and $18 /$ 45 cycles, the $\mathrm{SrBr}_{2} \cdot 6 \mathrm{H}_{2} \mathrm{O}$ and $\mathrm{CaCl}_{2} \cdot 4 \mathrm{H}_{2} \mathrm{O}$ are stable, respectively (Figure 6a). Therefore, the calculation does not 
Table 3. Salt-Based Composites and Their Heat Storage Densities under Conditions of Heat Storage Cycles Relevant for Domestic Heating Applications ${ }^{a}$

\begin{tabular}{|c|c|c|c|c|c|c|}
\hline salt hydrate & matrix or binder & GSD $(\mathrm{MJ} / \mathrm{kg})$ & $\operatorname{VSD}^{b}\left(\mathrm{GJ} / \mathrm{m}^{3}\right)$ & $T_{\mathrm{e}} / T_{\mathrm{h}}\left({ }^{\circ} \mathrm{C}\right)$ & $\operatorname{VSD}_{\mathrm{e}}\left(\mathrm{MJ} / \mathrm{m}^{3}\right)$ & refs \\
\hline $\mathrm{CaCl}_{2} \cdot 6 \mathrm{H}_{2} \mathrm{O}$ & HS & 1.1 & $0.9 \pm 0.1$ & $13 / 45$ & 96 & this work \\
\hline $\mathrm{CaCl}_{2} \cdot 6 \mathrm{H}_{2} \mathrm{O}$ & ethylcellulose & 2.1 & 0.4 & $10 / 20$ & 14 & 45 \\
\hline $\mathrm{CaCl}_{2} \cdot 6 \mathrm{H}_{2} \mathrm{O}$ & $\mathrm{SiO}_{2}$ (Grace Davisil) & 1.1 & 0.76 & $10 / 30$ & 54 & 46 \\
\hline $\mathrm{CaCl}_{2} \cdot 6 \mathrm{H}_{2} \mathrm{O}$ & silica-alumina & 0.9 & 0.65 & $3 / 20$ & 40 & 47 \\
\hline $\mathrm{CaCl}_{2} \cdot 6 \mathrm{H}_{2} \mathrm{O}$ & PHTS & 1.2 & & $10 / 30$ & & 48 \\
\hline $\mathrm{CaCl}_{2} \cdot 6 \mathrm{H}_{2} \mathrm{O}$ & MIL-101(Cr) & 1.6 & 1.0 & $10 / 30$ & 71 & 22 \\
\hline $\mathrm{LiCl} \cdot \mathrm{H}_{2} \mathrm{O}$ & HS & 0.75 & $0.65 \pm 0.10$ & $13 / 45$ & 73 & this work \\
\hline $\mathrm{LiCl} \cdot \mathrm{H}_{2} \mathrm{O}$ & HS & 0.63 & $0.5 \pm 0.1$ & $13 / 60$ & 85 & this work \\
\hline $\mathrm{LiCl} \cdot \mathrm{H}_{2} \mathrm{O}$ & PVA + MWCNT & 1.6 & & $10 / 35$ & & 49 \\
\hline $\mathrm{LiCl} \cdot \mathrm{H}_{2} \mathrm{O}$ & expanded vermiculite & $>1.8$ & 0.8 & $10 / 35$ & 70 & 50 \\
\hline $\mathrm{LiCl} \cdot \mathrm{H}_{2} \mathrm{O}$ & $\mathrm{SiO}_{2}$ (Fuji Type A) & 1.1 & 0.6 & $15 / 40$ & 52 & 51 \\
\hline $\mathrm{SrBr}_{2} \cdot 6 \mathrm{H}_{2} \mathrm{O}$ & HS & 0.69 & $0.6 \pm 0.1$ & $18 / 45$ & 59 & this work \\
\hline $\mathrm{SrBr}_{2} \cdot 6 \mathrm{H}_{2} \mathrm{O}$ & expanded vermiculite & 1.6 & 0.38 & $20 / 30$ & 13 & 52 \\
\hline $\mathrm{SrBr}_{2} \cdot 6 \mathrm{H}_{2} \mathrm{O}$ & MIL-101(Cr) & 1.35 & 0.84 & $10 / 30$ & 59 & 37 \\
\hline $\mathrm{K}_{2} \mathrm{CO}_{3} \cdot 1.5 \mathrm{H}_{2} \mathrm{O}$ & expanded vermiculite & & 0.9 & $20 / 30$ & 31 & 53 \\
\hline $\mathrm{K}_{2} \mathrm{CO}_{3} \cdot 1.5 \mathrm{H}_{2} \mathrm{O}$ & (bed of pills) & 0.9 & 0.7 & $10 / 40$ & 70 & \\
\hline $\mathrm{MgCl}_{2} \cdot 6 \mathrm{H}_{2} \mathrm{O}$ & zeolites $(13 \times, \mathrm{NaY})$ & 1.2 & & $10 / 20$ & & 54 \\
\hline $\mathrm{MgSO}_{4} \cdot 7 \mathrm{H}_{2} \mathrm{O}$ & zeolite $13 \times$ & 0.65 & 0.6 & $15 / 20$ & 10 & 55 \\
\hline
\end{tabular}

${ }^{a}$ The charging temperatures $T_{\mathrm{d}}<100{ }^{\circ} \mathrm{C}$ for all of the references. ${ }^{b}$ Per $1 \mathrm{~m}^{3}$ of a composite bed.

account for the second and the third terms in eq 11 . For $\mathrm{LiCl}$, all of the terms are present for the $13 / 45$ cycle, while only the chemical reaction is accounted for in the 13/60 cycle.

The resultant heat storage densities presented in Table 3 show that the core-shell encapsulation method can provide state-of-the-art VSD (up to $0.86 \mathrm{GJ} / \mathrm{m}^{3}$ ) while providing hightemperature uplift $\left(T_{\mathrm{h}}-T_{\mathrm{e}}\right)$, as illustrated in Figure 8.

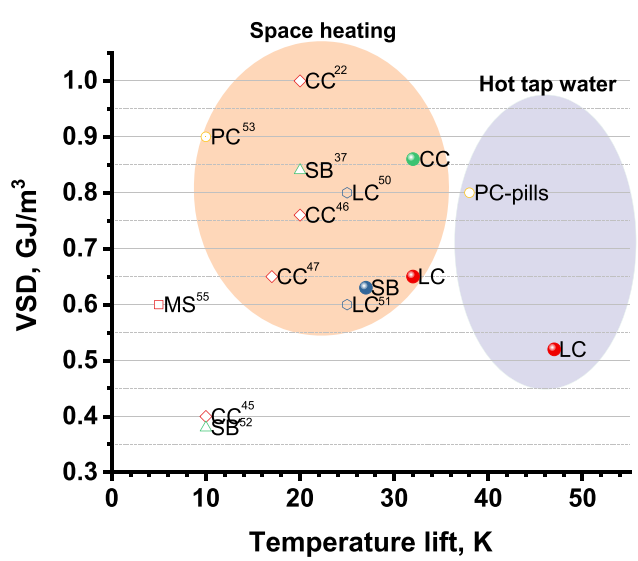

Figure 8. Comparison of volumetric storage density (VSD) for the composites and the temperature lift for heat storage cycles. The data are taken from Table 3. Empty symbols represent the literature data, filled ones-the values obtained in this work. The coding for the salts is as follows: $\mathrm{CC}-\mathrm{CaCl}_{2}, \mathrm{PC}-\mathrm{K}_{2} \mathrm{CO}_{3}$ ( $\mathrm{PC}$ pills are pressed pills of high density), $\mathrm{LC}-\mathrm{LiCl}, \mathrm{SB}-\mathrm{SrBr}_{2}$, and $\mathrm{MS}-\mathrm{MgSO}_{4}$.

Compared to the current highest VSD reported for composites "salt in the porous matrix", $\mathrm{CaCl}_{2} / \mathrm{MIL}-101(\mathrm{Cr}), \mathrm{CaCl}_{2} @ \mathrm{HS}$ shows almost similar heat storage density while providing some $32 \mathrm{~K}$ temperature uplift as compared with $20 \mathrm{~K}$ for $\mathrm{CaCl}_{2}$ / MIL-101(Cr). ${ }^{22}$ LiCl@HS can provide even higher temperature lift of $47 \mathrm{~K}$ while conserving promising heat storage density of $0.52 \mathrm{GJ} / \mathrm{m}^{3}$. Thus, the correct comparison should include not only VSD but also the cycle efficiency, as the former can be boosted at the expense of the later.
A measure that can characterize both VSD and efficiency of a cycle should account for temperature uplift $\Delta T=T_{\mathrm{h}}-T_{\mathrm{e}}$ and evaporation temperature. The best heat storage system would provide the highest VSD for the conditions with the highest $\Delta T$ and low $T_{\mathrm{e}}$. The $\mathrm{VSD}_{\mathrm{e}}$ value can then be obtained as

$$
\operatorname{VSD}_{\mathrm{e}}=\operatorname{VSD} \times \Delta T / T_{\mathrm{e}}=\operatorname{VSD}\left(\frac{T_{\mathrm{h}}-T_{\mathrm{e}}}{T_{\mathrm{e}}}\right)
$$

The physical meaning of $\mathrm{VSD}_{\mathrm{e}}$ is the amount of exergy stored per $1 \mathrm{~m}^{3}$ of the bed. The analysis of $\mathrm{VSD}_{\mathrm{e}}$ from Table 3 shows that $\mathbf{L i C l} @ H S$ and $\mathbf{C a C l}_{2} @ H S$ show the highest $\mathrm{VSD}_{\mathrm{e}}$ values reported. This demonstrates an excellent potential of $\mathbf{H S}$ as a host for the salt encapsulation.

It is noteworthy that the VSD may be optimized for a particular application by the proper design of the system that would depend on the desired application. If one considers only the production of hot tap water, e.g., the 13/60 cycle for $\mathrm{LiCl}$, then the heat is released/stored only due to process (6) and it would be optimal to maximize the loading of the salt into the spheres by multiple impregnation/drying. In this case, the VSD is limited by "useful porosity" of the bed $(52.1 \pm 0.3 \%$, Table $\mathrm{S} 1$ in the SI) that would give $1.09 \pm 0.06 \mathrm{GJ} / \mathrm{m}^{3}$ of $\mathrm{LiCl} @ \mathrm{HS}$. On the other hand, releasing heat at $30^{\circ} \mathrm{C}$ by $\mathrm{CaCl}_{2}$ for space heating would entail diluting the solution more and exceed the water uptake threshold for $\mathrm{CaCl}_{2} @ \mathrm{HS}$ reported in this work. Additional optimization parameters are shell porosity, capsule size, and thickness. However, due to almost the densest packing of the spheres, these parameters affect the VSD only slightly (Figure S5 in the SI). Thus, the optimization of the salt content can be done for particular applications in the course of further work.

3.4. Cycling Stability. In this work, we subject the salt@ HS materials to comprehensive stability tests. $\mathbf{C a C l}_{2} @ \mathrm{HS}$ and $\mathrm{SrBr}_{2} @ H S$ show excellent conversion stability over at least 20 cycles, as evidenced from Figure 9. Under the conditions of the cycle only solid-solid transformations occur. In contrast, for LiCl@HS the conditions were chosen for dissolution- 


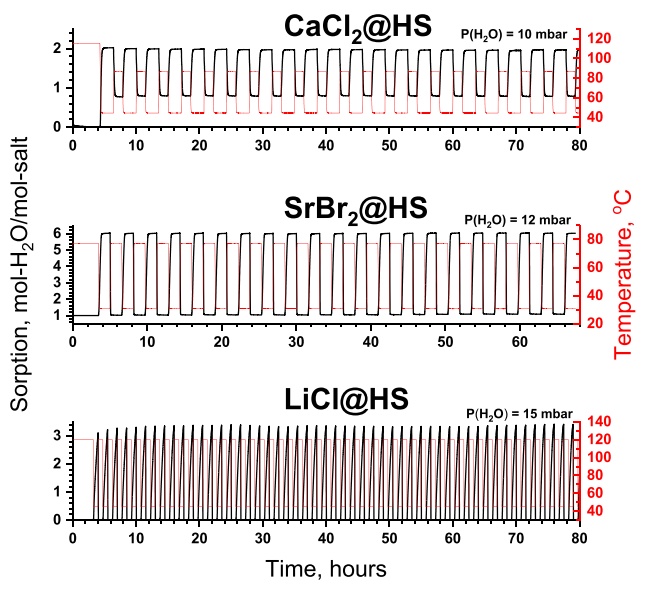

Figure 9. TG-curves of the cycling for the salt@HS. The cycling was carried out by temperature swinging while maintaining the $P\left(\mathrm{H}_{2} \mathrm{O}\right)$ in the reaction chamber constant. The $P\left(\mathrm{H}_{2} \mathrm{O}\right)$ values for $\mathrm{CaCl}_{2} @ \mathrm{HS}$, $\mathrm{SrBr}_{2} @ \mathrm{HS}$, and LiCl@HS are 10, 12, and 15 mbar, respectively.

recrystallization transition. The conversion was found to be stable for at least 50 cycles with almost maximal water uptake for this material (Figure 9).

The cycled LiCl@HS was washed with water two times to check the mechanical stability of the capsules by TEM. From the images (Figure 10), one can see that initially the free space in the capsules looks evenly distributed. However, after multiple dissolution-recrystallization, the empty space in the capsules is clearly visible due to its redistribution in the course of multiple dissolution-recrystallization (see also Figure S4 in the SI). Finally, the washed capsules, while containing some residual $\mathrm{LiCl}$, conserve their shape and texture being mechanically stable, as can be concluded from the right picture in Figure 10.

\section{CONCLUSIONS}

In this work, we investigate the composites of salt hydrates encapsulated in mesoporous silica shells. It was shown that the composites can be readily prepared by impregnation of the salt solutions $\left(\mathrm{CaCl}_{2}, \mathrm{SrBr}_{2}, \mathrm{LiCl}\right)$ in the silica shells, which themselves can be obtained by a facile synthesis.

The composites were investigated by a series of physicochemical methods (XRD, BET, SEM, TEM). The encapsulation of the salts in the spheres was confirmed with part of the salt apparently being confined into the mesopores of the shell.

The sorption equilibrium of the salts was reported. The heat storage density on the bed level was found to be close to the state-of-the-art values for the composites peaking at $0.9 \pm 0.1$ $\mathrm{GJ} / \mathrm{m}^{3}$ for $\mathrm{CaCl}_{2} @ \mathrm{HS}$ for a cycle with the high-temperature uplift of $32{ }^{\circ} \mathrm{C}$. Based on effective volumetric heat storage density, we conclude that the HS exhibits an excellent potential as a host matrix for efficient salt encapsulation. The stability of cyclic behavior and mechanical integrity of the capsules was confirmed for at least 50 hydration/dehydration cycles for LiCl@HS.

Although the salt@HS system was not pushed to its limit in this work, the authors believe that in the future, the volumetric storage density may be boosted up to $1.1 \mathrm{GJ} / \mathrm{m}^{3}$ for a hot tap water production cycle $\left(\mathrm{LiCl}, T_{\mathrm{e}}=13{ }^{\circ} \mathrm{C}, T_{\mathrm{h}}=60{ }^{\circ} \mathrm{C}\right)$ by modifying the preparation procedure. The obtained composite may thus represent a basis for the creation of compact saltbased heat accumulators for domestic applications in the future.

\section{ASSOCIATED CONTENT}

\section{SI Supporting Information}

The Supporting Information is available free of charge at https://pubs.acs.org/doi/10.1021/acsaem.0c00971.

Parameters for hollow spheres (HS); $\mathrm{N}_{2}$ sorption isotherms and cumulative pore volume $(\mathrm{BJH})$; SEM images of LiCl@HS; extra TEM images for LiCl@HS (including cycled) and $\mathbf{S r B r}_{2} @ H S$; evaluation of the effect of shell radius and porosity on VSD; photographs of the equipment (PDF)

\section{AUTHOR INFORMATION}

\section{Corresponding Author}

Alexandr Shkatulov - Eindhoven University of Technology, Department of Applied Physics, 5612 AP Eindhoven, The Netherlands; 이이이.org/0000-0002-9765-104X; Email: a.shkatulov@tue.nl

\section{Authors}

Rick Joosten - Eindhoven University of Technology, Department of Chemical Engineering and Chemistry, Center for Multiscale Electron Microscopy, 5600 MB Eindhoven, The Netherlands

Hartmut Fischer - Netherlands Organization for Applied Scientific Research (TNO), 5656 AE Eindhoven, The Netherlands

Henk Huinink - Eindhoven University of Technology, Department of Applied Physics, 5612 AP Eindhoven, The Netherlands

Complete contact information is available at: https://pubs.acs.org/10.1021/acsaem.0c00971

\section{Author Contributions}

This manuscript was written through contributions of all authors. All authors have given approval to the final version of
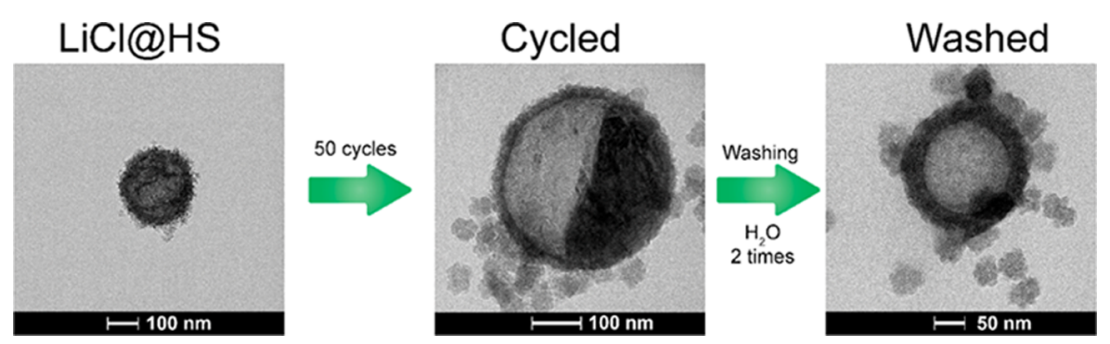

Figure 10. TEM images of the as-prepared LiCl@HS (left, $50 \mathrm{k} \times$ ) after 50 hydration/dehydration cycles (middle, $80 \mathrm{k} \times$ ) and washed twice after cycling (right, $100 \mathrm{k} \times$ ). 
the manuscript. A.S. developed the idea, prepared the materials, designed experiments, and wrote the manuscript, R.J. performed TEM imaging, H.F. and H.H. took part in the discussion of the results and the manuscript preparation.

\section{Funding}

All authors received funding from the TKI Urban Energy project Cap4Heat (\#1407201)

\section{Notes}

The authors declare no competing financial interest.

\section{ACKNOWLEDGMENTS}

The authors thank the Dutch TKI Urban Energy program (project Cap4Heat, \#1407201) for financial support. The authors are grateful to Dr. H. Friedrich for discussing the TEM experiments and commenting on the manuscript, M. Solovyeva for assistance with nitrogen adsorption measurements and $\mathrm{O}$. Naumov for assistance with the TOC graph.

\section{REFERENCES}

(1) Gur, I.; Sawyer, K.; Prasher, R. Searching for a Better Thermal Battery. Science 2012, 335, 1454-1455.

(2) Gutierrez, A.; Ushak, S.; Linder, M. High Carnallite-Bearing Material for Thermochemical Energy Storage: Thermophysical Characterization. ACS Sustainable Chem. Eng. 2018, 6, 6135-6145.

(3) Li, R.; Shi, Y.; Shi, L.; Alsaedi, M.; Wang, P. Harvesting Water from Air: Using Anhydrous Salt with Sunlight. Environ. Sci. Technol. 2018, 52, 5398-5406.

(4) Donkers, P. A. J.; Sögütoglu, L. C.; Huinink, H. P.; Fischer, H. R.; Adan, O. C. G. A Review of Salt Hydrates for Seasonal Heat Storage in Domestic Applications. Appl. Energy 2017, 199, 45-68.

(5) Shizume, K.; Hatada, N.; Toyoura, K.; Uda, T. Characteristic Microstructure Underlying the Fast Hydration-Dehydration Reaction of $\beta-\mathrm{La}_{2}\left(\mathrm{SO}_{4}\right)_{3}$ : "Fine Platy Joints" with "Loose Grain Boundaries.". J. Mater. Chem. A 2018, 6, 24956-24964.

(6) Knoll, C.; Müller, D.; Artner, W.; Welch, J. M.; Werner, A.; Harasek, M.; Weinberger, P. Probing Cycle Stability and Reversibility in Thermochemical Energy Storage $-\mathrm{CaC}_{2} \mathrm{O}_{4} \cdot \mathrm{H}_{2} \mathrm{O}$ as Perfect Match? Appl. Energy 2017, 187, 1-9.

(7) Afflerbach, S.; Kowald, T.; Trettin, R. Phase Transformations during De- and Rehydration of Scholzite CaZn $\mathrm{C}_{2}\left(\mathrm{PO}_{4}\right)_{2} \cdot 2 \mathrm{H}_{2} \mathrm{O}$. J. Solid State Chem. 2017, 254, 184-194.

(8) Kiyabu, S.; Lowe, J. S.; Ahmed, A.; Siegel, D. J. Computational Screening of Hydration Reactions for Thermal Energy Storage: New Materials and Design Rules. Chem. Mater. 2018, 30, 2006-2017.

(9) Sögütoglu, L.-C.; Steiger, M.; Houben, J.; Biemans, D.; Fischer, H. R.; Donkers, P.; Huinink, H.; Adan, O. C. G. Understanding the Hydration Process of Salts: The Impact of a Nucleation Barrier. Cryst. Growth Des. 2019, 19, 2279-2288.

(10) Carrillo, A. J.; González-Aguilar, J.; Romero, M.; Coronado, J. M. Solar Energy on Demand: A Review on High Temperature Thermochemical Heat Storage Systems and Materials. Chem. Rev. 2019, 119, 4777-4816.

(11) Zhang, Y.; Wang, R. Sorption Thermal Energy Storage: Concept, Process, Applications and Perspectives. Energy Storage Mater. 2020, 27, 352-369.

(12) Ammann, J.; Ruch, P.; Michel, B.; Studart, A. R. High-Power Adsorption Heat Pumps Using Magnetically Aligned Zeolite Structures. ACS Appl. Mater. Interfaces 2019, 11, 24037-24046.

(13) Kim, H.; Yang, S.; Rao, S. R.; Narayanan, S.; Kapustin, E. A.; Furukawa, H.; Umans, A. S.; Yaghi, O. M.; Wang, E. N. Water Harvesting from Air with Metal-Organic Frameworks Powered by Natural Sunlight. Science 2017, 356, 430-434.

(14) Lee, J. S.; Yoon, J. W.; Mileo, P. G. M.; Cho, K. H.; Park, J.; Kim, K.; Kim, H.; De Lange, M. F.; Kapteijn, F.; Maurin, G.; Humphrey, S. M.; Chang, J.-S. Porous Metal-Organic Framework CUK-1 for Adsorption Heat Allocation toward Green Applications of
Natural Refrigerant Water. ACS Appl. Mater. Interfaces 2019, 11, 25778-25789.

(15) Water in Crystalline Hydrates Aqueous Solutions of Simple Nonelectrolytes; Franks, F., Ed.; Springer US: Boston, MA, 1973.

(16) Sögütoglu, L. C.; Donkers, P. A. J.; Fischer, H. R.; Huinink, H. P.; Adan, O. C. G. In-Depth Investigation of Thermochemical Performance in a Heat Battery: Cyclic Analysis of $\mathrm{K}_{2} \mathrm{CO}_{3}, \mathrm{MgCl}_{2}$ and $\mathrm{Na}_{2}$ S. Appl. Energy 2018, 215, 159-173.

(17) Chizhik, S.; Matvienko, A.; Sidelnikov, A. Spatially-Ordered Nano-Sized Crystallites Formed by Dehydration-Induced Single Crystal Cracking of $\mathrm{CuCl}_{2} \cdot 2\left(\mathrm{H}_{2} \mathrm{O}\right)$. CrystEngComm 2018, 20, 6005-6017.

(18) Calabrese, L.; Brancato, V.; Palomba, V.; Frazzica, A.; Cabeza, L. F. Magnesium Sulphate-Silicone Foam Composites for Thermochemical Energy Storage: Assessment of Dehydration Behaviour and Mechanical Stability. Sol. Energy Mater. Sol. Cells 2019, 200, No. 109992.

(19) Gordeeva, L. G.; Aristov, Y. I. Composites "salt inside Porous Matrix" for Adsorption Heat Transformation: A Current State-of-theArt and New Trends. Int. J. Low-Carbon Technol. 2012, 7, 288-302.

(20) Zhang, Y. N.; Wang, R. Z.; Li, T. X. Thermochemical Characterizations of High-Stable Activated Alumina/LiCl Composites with Multistage Sorption Process for Thermal Storage. Energy 2018, $156,240-249$.

(21) Yu, N.; Wang, R. Z.; Lu, Z. S.; Wang, L. W. Study on Consolidated Composite Sorbents Impregnated with $\mathrm{LiCl}$ for Thermal Energy Storage. Int. J. Heat Mass Transfer 2015, 84, 660670

(22) Permyakova, A.; Wang, S.; Courbon, E.; Nouar, F.; Heymans, N.; D’Ans, P.; Barrier, N.; Billemont, P.; Weireld, G. D.; Steunou, N.; Frère, M.; Serre, C. Design of Salt-Metal Organic Framework Composites for Seasonal Heat Storage Applications. J. Mater. Chem. A 2017, 5, 12889-12898.

(23) Tokarev, M. M.; Gordeeva, L. G.; Shkatulov, A. I.; Aristov, Y. I. Testing the Lab-Scale "Heat from Cold" Prototype with the "LiCl/ Silica - Methanol" Working Pair. Energy Convers. Manage. 2018, 159, 213-220.

(24) Li, W.; Guo, H.; Zeng, M.; Wang, Q. Performance of $\mathrm{SrBr}_{2}$. $6 \mathrm{H}_{2} \mathrm{O}$ Based Seasonal Thermochemical Heat Storage in a Novel Multilayered Sieve Reactor. Energy Convers. Manage. 2019, 198, No. 111843.

(25) Zhao, Y. J.; Wang, R. Z.; Zhang, Y. N.; Yu, N. Development of $\mathrm{SrBr}_{2}$ Composite Sorbents for a Sorption Thermal Energy Storage System to Store Low-Temperature Heat. Energy 2016, 115, 129-139.

(26) Nuruzzaman, M.; Ren, J.; Liu, Y.; Rahman, M. M.; Shon, H. K.; Naidu, R. Hollow Porous Silica Nanosphere with Single Large Pore Opening for Pesticide Loading and Delivery. ACS Appl. Nano Mater. 2020, 3, 105-113.

(27) Mo, Y.; Liu, J.; Zhong, L.; Xiao, M.; Ren, S.; Han, D.; Wang, S.; Meng, Y. Hierarchical NiCoP/C Hollow Nanoflowers for Enhanced Lithium Storage. ACS Appl. Nano Mater. 2019, 2, 6880-6888.

(28) Shchukina, E. M.; Graham, M.; Zheng, Z.; Shchukin, D. G. Nanoencapsulation of Phase Change Materials for Advanced Thermal Energy Storage Systems. Chem. Soc. Rev. 2018, 47, 4156-4175.

(29) Graham, M.; Shchukina, E.; De Castro, P. F.; Shchukin, D. Nanocapsules Containing Salt Hydrate Phase Change Materials for Thermal Energy Storage. J. Mater. Chem. A 2016, 4, 16906-16912.

(30) Song, S.; Zhao, T.; Zhu, W.; Qiu, F.; Wang, Y.; Dong, L. Natural Microtubule-Encapsulated Phase-Change Material with Simultaneously High Latent Heat Capacity and Enhanced Thermal Conductivity. ACS Appl. Mater. Interfaces 2019, 11, 20828-20837.

(31) Do, T.; Ko, Y. G.; Jung, Y.; Choi, U. S. Highly Durable and Thermally Conductive Shell-Coated Phase-Change Capsule as a Thermal Energy Battery. ACS Appl. Mater. Interfaces 2020, 12, 57595766.

(32) Recent Advancements in Materials and Systems for Thermal Energy Storage: An Introduction to Experimental Characterization Methods. In Green Energy and Technology; Frazzica, A.; Cabeza, L. F., Eds.; Springer International Publishing: Cham, 2019. 
(33) Afflerbach, S.; Kappes, M.; Gipperich, A.; Trettin, R.; Krumm, W. Semipermeable Encapsulation of Calcium Hydroxide for Thermochemical Heat Storage Solutions. Sol. Energy 2017, 148, 111.

(34) Du, B.; Cao, Z.; Li, Z.; Mei, A.; Zhang, X.; Nie, J.; Xu, J.; Fan, Z. One-Pot Preparation of Hollow Silica Spheres by Using Thermosensitive Poly(N-Isopropylacrylamide) as a Reversible Template. Langmuir 2009, 25, 12367-12373.

(35) Utashiro, Y.; Takiguchi, M.; Satoh, M. Zeta Potential of PNIPAM Microgel Particles Dispersed in Water-Effects of Charged Radical Initiators vs. OH- Ion Adsorption. Colloid Polym. Sci. 2017, 295, 45-52.

(36) Hales, T. C. An Overview of the Kepler Conjecture, arXiv:math/9811071. arXiv.org e-Print archive. https://arxiv.org/ abs/math/9811071 (revised May 20,2002).

(37) D’Ans, P.; Courbon, E.; Permyakova, A.; Nouar, F.; SimonnetJégat, C.; Bourdreux, F.; Malet, L.; Serre, C.; Frère, M.; Steunou, N. A New Strontium Bromide MOF Composite with Improved Performance for Solar Energy Storage Application. J. Energy Storage 2019, 25, No. 100881.

(38) Glasser, L. Thermodynamics of Inorganic Hydration and of Humidity Control, with an Extensive Database of Salt Hydrate Pairs. J. Chem. Eng. Data 2014, 59, 526-530.

(39) Greenspan, L. Humidity Fixed Points of Binary Saturated Aqueous Solutions. J. Res. Natl. Bur. Stand., Sect. A 1977, 81A, No. 89.

(40) Richardson, G. M.; Malthus, R. S. Salts for Static Control of Humidity at Relatively Low Levels. J. Appl. Chem. 1955, 5, 557-567.

(41) Shkatulov, A.; Gordeeva, L. G.; Girnik, I.; Huinink, H. P.; Aristov, Y. I. Novel Adsorption Method for Moisture and Heat Recuperation in Ventilation: Composites "LiCl/Matrix" Tailored for Cold Climate. Energy 2020, 201, No. 117595.

(42) Wolf, G.; Jahn, H.; Pekárek, V.; Vacek, V. Enthalpy of Dissolution of $\mathrm{LiCl}$ and $\mathrm{LiCl} \cdot \mathrm{H}_{2} \mathrm{O}$ in Water at $25{ }^{\circ} \mathrm{C}$ at Low Concentrations. Thermochim. Acta 1987, 116, 291-299.

(43) Pátek, J.; Klomfar, J. Solid-Liquid Phase Equilibrium in the Systems of $\mathrm{LiBr}-\mathrm{H}_{2} \mathrm{O}$ and $\mathrm{LiCl}-\mathrm{H} 2 \mathrm{O}$. Fluid Phase Equilib. 2006, 250, 138-149.

(44) Conde, M. R. Properties of Aqueous Solutions of Lithium and Calcium Chlorides: Formulations for Use in Air Conditioning Equipment Design. Int. J. Therm. Sci. 2004, 43, 367-382.

(45) Gaeini, M.; Rouws, A.; Salari, J.; Zondag, H.; Rindt, C. Characterization of Microencapsulated and Impregnated Porous Host Materials Based on Calcium Chloride for Thermochemical Energy Storage. Appl. Energy 2018, 212, 1165-1177.

(46) Courbon, E.; D’Ans, P.; Permyakova, A.; Skrylnyk, O.; Steunou, N.; Degrez, M.; Frère, M. Further Improvement of the Synthesis of Silica Gel and $\mathrm{CaCl}_{2}$ Composites: Enhancement of Energy Storage Density and Stability over Cycles for Solar Heat Storage Coupled with Space Heating Applications. Sol. Energy 2017, 157, 532-541.

(47) Jabbari-Hichri, A.; Bennici, S.; Auroux, A. Enhancing the Heat Storage Density of Silica-Alumina by Addition of Hygroscopic Salts $\left(\mathrm{CaCl}_{2}, \mathrm{Ba}(\mathrm{OH})_{2}\right.$, and $\left.\mathrm{LiNO}_{3}\right)$. Sol. Energy Mater. Sol. Cells 2015, 140, 351-360.

(48) Ristić, A.; Zabukovec Logar, N. New Composite Water Sorbents CaCl2-PHTS for Low-Temperature Sorption Heat Storage: Determination of Structural Properties. Nanomaterials 2019, 9, No. 27.

(49) Brancato, V.; Gordeeva, L. G.; Grekova, A. D.; Sapienza, A.; Vasta, S.; Frazzica, A.; Aristov, Y. I. Water Adsorption Equilibrium and Dynamics of LICL/MWCNT/PVA Composite for Adsorptive Heat Storage. Sol. Energy Mater. Sol. Cells 2019, 193, 133-140.

(50) Grekova, A. D.; Gordeeva, L. G.; Aristov, Y. I. Composite

"LiCl/Vermiculite" as Advanced Water Sorbent for Thermal Energy Storage. Appl. Therm. Eng. 2017, 124, 1401-1408.

(51) Yu, N.; Wang, R. Z.; Lu, Z. S.; Wang, L. W. Development and Characterization of Silica Gel-LiCl Composite Sorbents for Thermal Energy Storage. Chem. Eng. Sci. 2014, 111, 73-84.

(52) Zhang, Y. N.; Wang, R. Z.; Zhao, Y. J.; Li, T. X.; Riffat, S. B.; Wajid, N. M. Development and Thermochemical Characterizations of
Vermiculite/ $\mathrm{SrBr}_{2}$ Composite Sorbents for Low-Temperature Heat Storage. Energy 2016, 115, 120-128.

(53) Shkatulov, A. I.; Houben, J.; Fischer, H.; Huinink, H. P. Stabilization of $\mathrm{K}_{2} \mathrm{CO}_{3}$ in Vermiculite for Thermochemical Energy Storage. Renewable Energy 2019, 150, 990-1000.

(54) Whiting, G. T.; Grondin, D.; Stosic, D.; Bennici, S.; Auroux, A. Zeolite- $\mathrm{MgCl} 2$ Composites as Potential Long-Term Heat Storage Materials: Influence of Zeolite Properties on Heats of Water Sorption. Sol. Energy Mater. Sol. Cells 2014, 128, 289-295.

(55) Hongois, S.; Kuznik, F.; Stevens, P.; Roux, J.-J. Development and Characterisation of a New $\mathrm{MgSO}_{4}$-zeolite Composite for LongTerm Thermal Energy Storage. Sol. Energy Mater. Sol. Cells 2011, 95, $1831-1837$. 